\title{
Design estratégico e a emergência da COVID-19
}

Debora Barauna;

Fernando G. Horlle;

Karine Freire

resumo:

A crise pandêmica da COVID-19 acabou por revelar a complexidade das situações adversas e o impacto dessas gerado em diversas camadas da existência humana. Diante disso, neste artigo, questiona-se a importância de um agir estratégico do design. Objetiva-se, então, dissertar o sobre o surgimento e a evolução do conceito de design estratégico como uma cultura emergente que se forma para o enfrentamento de situações complexas. O estudo se dá por meio de uma revisão narrativa e cronológica de obras de Ezio Manzini, com colaborações pontuais de Ana Meroni e Arturo Escobar, até se chegar em um recorte de iniciativas internacionais de design, interessadas em contribuir estrategicamente com o cenário pandêmico vivido. De maneira geral, as visões conceituais retóricas apontadas por Manzini mostram a atualidade e relevância de uma cultura de design capaz de operar na emergência, ressignificando e hibridizando relações ecossistêmicas entre mundos físicos e digitais e propondo soluções sociotécnicas.

palavras-chave:

Design Estratégico; COVID-19; Situações Complexas; Cultura de Design; Hibridismo 


\section{Introdução}

Visões de mudança na cultura do design já ocorrem na literatura desde a publicação "Design for the real world", em 1971, do designer visionário Victor Papanek. Porém, viver uma situação pandêmica, como a doença COVID-19 (COrona VIrus Disease) ou Síndrome Respiratória Aguda Grave Coronavírus 2 (SARS-CoV-2), trouxe à tona a relevância do papel estratégico do design diante do enfrentamento de situações adversas, incertas, emergentes. O design estratégico é uma metodologia que projeta a partir dos ecossistemas e visa a equidade e o bem-estar social. Para isso, opera com uma postura crítica-criativa sobre o mundo e formativa do ponto de vista de uma nova cultura de design, considerando-a uma agente de mudanças.

Para Newbigin, Rosselló e Wright (2010, p. 16) "a criatividade é um processo disruptivo que questiona limites e pressupostos estabelecidos [...]. A criatividade impulsiona a inovação e a inovação impulsiona mudanças". Com isso, há uma criatividade aflorada em novos sistemas, processos, produtos e serviços, o que tem realçado o conceito de uma economia criativa. Este é um tipo de economia que tem na base dos seus negócios a inventividade, a criação de significados, a produção de cultura, e se refere à diversidade cultural, à inclusão social e à sustentabilidade (MADEIRA, 2014; NEWBIGIN, 2016). Neste contexto é que se insere o Programa de Pós-Graduação em Design da Escola da Indústria Criativa da Universidade do Vale do Rio do Sinos (UNISINOS), empenhado na formação de mestres e doutores em Design Estratégico. Sendo este artigo reflexo de discussões provocadas por uma atividade acadêmica sobre o agir estratégico do design em plena pandemia mundial.

Diante deste contexto, a questão posta neste artigo é: como a situação da COVID-19 revela a importância do conceito de design estratégico? O objetivo é, então, dissertar sobre o surgimento e a evolução do design estratégico como uma cultura de design que se forma para o enfrentamento, de modo crítico-criativo, de situações de interações complexas, tal como se mostrou os efeitos do coronavírus em diferentes dimensões da existência humana.

$\mathrm{O}$ designer, arquiteto e engenheiro Ezio Manzini, ao longo de sua trajetória, enquanto pesquisador, já vem discutindo sobre a evolução dos modos de operar do design sobre o mundo. O que se pretende, então, nesta revisão narrativa da literatura, é promover um resgate retórico das visões do autor, dissertando sobre elas até chegar na relação do design com a crise pandêmica mundial vivida no início do século XXI. Este já era um período taxado para sofrer muitas mudanças, todavia, a COVID19 fez por acelerar o processo.

No artigo segue-se então uma sequência cronológica de visões ensaiadas por Manzini, que acabam por mostrar a necessidade de uma nova postura estratégica do design. Partindo do Prometeu do Cotidiano (Prometheus of the Everyday) de Manzini e Cullars (1992), apresentam-se sínteses de narrativas que consideram o design como uma cultura em transformação, evoluindo da compreensão de uma nova ética do fazer para um design emergente, capaz de lidar com situações de interações complexas, tal como se revelou na pandemia da COVID-19.

Além de Manzini, cita-se também a designer Anna Meroni (2008), que narrou a evolução de quase uma década do conceito de design estratégico, desde a publicação "Design Estratégico para Sustentabilidade" de Manzini (1999), e, também, o sociólogo Arturo Escobar, que, em ensaio de 2018, corrobora a visão de haver uma cultura emergente de design preocupada em agir na mudança, e que está projetando para um novo mundo.

\section{Design de Manzini para um novo mundo}

Na narrativa do Prometeu do Cotidiano, Manzini e Cullars (1992) já sinalizavam que o design, na busca de entender a complexidade e agir dentro dos limites do planeta, passava a adotar uma nova postura, uma nova ética do fazer: deve-se dar passagem à cultura de fazer como produção e dar lugar para um fazer como reprodução. Para os autores, isso significa criar condições que permitam a manutenção da continuação da existência, assumindo um princípio ético de permanência de um mundo habitável, rico em possibilidades e interações para todas as próximas gerações - e isso deve se tornar a prática cotidiana.

Alguns outros pontos de vista dos autores, neste sentido, também se destacam na narrativa de 1992, esses são: 
- Com a descoberta dos limites ambientais, os objetivos "projetar e produzir" passaram por um processo de ressignificação, questionado o motivo pelo qual e para quem coisas são projetadas e produzidas.

- É da natureza humana fazer, arraigada em um complexo de atividades históricas e socialmente construídas: trata-se de uma cultura do fazer. Na cultura ocidental moderna, o significado de fazer não pode continuar por uma razão prática - seu objetivo de dominar a natureza, pois se defronta com a situação que a natureza até "pode ser manipulada localmente, mas não dominada globalmente” (MANZINI E CULLARS, 1992, p. 9).

Por fim, em tal obra os autores ainda relatam que a existência e a difusão de produtos sem valor são reflexos da concepção de um mundo descartável, "um mundo de objetos sem profundidade que não deixa rastros em nossas memórias, mas deixa uma montanha crescente de lixo" (MANZINI e CULLARS, 1992, p. 7). Sendo os motivos provocadores disso tanto os avanços tecnológicos e o rápido impulso comercial desses, como a ausência de uma cultura de design capaz de enfrentar esses processos acelerados de desenvolvimento. Foi partindo dessas percepções que Manzini ensaiou sobre a abordagem do design estratégico, como um novo agir sobre o mundo; são novas relações que se estabelecem nele e com ele. Uma vez que "o grande projeto de simplificação da realidade está mostrando suas limitações. A complexidade sistêmica que foi jogada pela janela está entrando agora pela porta da frente" (MANZINI E CULLARS, 1992, p. 12).

\subsection{Design estratégico para a sustentabilidade: Manzini (1999)}

Nessa narrativa de 1999, Manzini segue apontando para a tentativa estratégica do design de agir sobre os limites do planeta e a melhora da vida cotidiana, apresentando a ideia da concepção integrada de um sistema de produtos, serviços e comunicação como um caminho para a sustentabilidade. Em tal sistema, o autor descreve existir dois tipos de estratégias, essas são: de curto prazo e longo prazo.

Pelo ponto de vista de estratégias de longo prazo, essas são maneiras mais diretas e imediatas de mudança (disruptivas), que exigem amplo incentivo e são difíceis de fazer. O objetivo dessas é levar o presente para o futuro, fazendo algo hoje para o amanhã. Já, estratégias de curto prazo para a sustentabilidade são avanços que se relacionam com a ideia de fazer algo hoje por hoje, mas que antecipa o amanhã, trazendo o futuro para o presente.

Em particular, a estratégia de curto prazo é "um conjunto de iniciativas que promovem uma mudança direta de um mix não sustentável de produtos e serviços para um (mais) sustentável" (MANZINI, 1999, p. 435) - são leves, de baixo custo, prazo imediato e praticáveis. Baseadas em novas ideias de negócios, com alteração do conceito de produto - do produto físico para o serviço do produto (SSP - Sistema Produto Serviço) - estratégias de curto prazo também requerem uma mudança na forma de pensar e agir das organizações, que desafia o modo tradicional de gerar negócios, com uma produção e um consumo reduzido. Isto pode parecer paradoxal, mas deveria ser a base de todas as empresas sustentáveis.

$\mathrm{Na}$ visão do autor, nesse processo, (I) sistemas ou combinações sustentáveis de produtos e serviços servem como um autosocorro para as empresas, (II) descontinuar sistemas ou combinações de produtos e serviços não sustentáveis por outro mais sustentável é um passo para a sustentabilidade e (III) se essas novas combinações são reconhecidas, aceitas, uma mudança no padrão pode ocorrer, considerando que, o que os usuários exigem não são produtos ou serviços, mas os efeitos resultantes da interação com esses (o que eles promovem).

Enfim, na transição para um modelo em que a sustentabilidade passará a ser um dos pontos centrais da sociedade, na qual (o autor faz uma provocação de futuro) as organizações serão obrigadas a viver contando com apenas $10 \%$ dos recursos ambientais utilizados hoje, o design estratégico mostra-se como um agente necessário de mudança. Já que, como reforça o autor, a busca por uma sociedade sustentável dificilmente ocorrerá a partir de melhorias do antigo paradigma voltado ao produto: é preciso considerar a importância de uma reorientação ambiental a partir do novo paradigma emergente de informações e serviços. Dentro desse novo paradigma, a abordagem é descrita através de 
uma orientação à utilidade, ou seja, a atuação das organizações passa ser por uma lógica de compartilhamento e não de posse.

Numa análise de quase dez anos, desde o surgimento do design estratégico, Meroni (2008) aponta um caminho para a sua evolução: do design centrado no usuário para o design centrado na comunidade. A autora ainda explica que todo projeto de design estratégico é um projeto SSP, mas nem todo SSP é design estratégico - este faz um sistema evoluir e não simplesmente desenvolver, pressupõe uma inovação radical, uma descontinuidade do sistema, agir por ele é tratar de evolução. Dentro deste contexto, a vertente do "design para a sustentabilidade é o design estratégico capaz de colocar em ato descontinuidades locais promissoras, contribuindo para efetivas mudanças sistêmicas" (MANZINI, 2008, p. 12). Aqui o autor já começava abordar a ideia de inovação social.

\subsection{Design para a inovação social: Manzini (2008)}

Uma inovação é aquela capaz de promover mudanças em padrões já estabelecidos. No conceito de inovação social, há "mudanças no modo como indivíduos ou comunidades agem para resolver seus problemas ou criar oportunidades" (MANZINI, 2008, p. 61).

Neste contexto, Manzini endereça a ideia de comunidades criativas, como um grupo de indivíduos, no qual o designer também se insere, que interagem entre si, em um processo social, para produzirem, juntos, soluções criativas para problemas sociais vigentes.

Desta forma, no design para a inovação social, o processo, geralmente, é gerido de modo horizontal, diante de demandas que emergem de baixo para cima, em vez daquelas de cima para baixo, segundo o autor. Sendo que as inovações sociais correspondem "tanto aos processos sociais de inovação como as inovações de interesse social, como também ao empreendedorismo de interesse social como suporte da ação inovadora" (MANZINI, 2008, p. 5).

$\mathrm{Na}$ visão do autor, a sociedade contemporânea, em sua complexidade, configura-se como um imenso laboratório de ideias para a vida cotidiana, onde modos de ser e fazer se concretizam em novas soluções criativas de bem-estar, qualidade de vida e sustentabilidade. Com isso, em todo o mundo têm surgido casos promissores de inovação social, seja na forma de serviços de colaboração social ou iniciativas de melhoria da qualidade de vida e bem-estar, como também sistemas de produção distribuídos em rede, que promovem o pequeno localmente e contribuem para a sustentabilidade global (MANZINI et al., 2010).

Conhecer esses casos tem sido o papel da Design for Social Innovation and Sustainability DESIS Network, que integra universidades em diversos países a fim de contribuir para a promoção de estratégias de replicação e soluções habilitantes de design. Estratégias de replicação são modos de multiplicar e conectar iniciativas, formando amplas redes; já soluções habilitantes ou facilitadoras de design definem-se como "um sistema de produtos, serviços, comunicação e o que mais for necessário para implementar a acessibilidade, a eficácia e a replicabilidade de uma organização colaborativa" (MANZINI, 2008, p. 84). Desde então, o conceito de design para a inovação social expandiu, formando uma nova cultura de design, cada vez mais, dialógica.

\subsection{Cultura de design e design dialógico: Manzini (2016)}

Nas visões anteriores do autor, o design já passa a se tornar um processo social e colaborativo, então aqui ele disserta sobre como a cultura de design se transforma em uma cultura dialógica, sendo o codesign a nova base do design e seus métodos.

O codesign é um processo que envolve vários atores, dentre eles o designer, que agem coletivamente para transformar situações complexas, relacionadas a todos os tipos de organizações (comunidade, sociedade, empresas, governo). Os atores desse processo são determinados pelo autor como "designers difusos e designers especialistas". Esses são papéis mais profundamente apresentados no texto "Design: quando todos fazem design", publicado por Manzini em 2015 e traduzido no Brasil em 2017. Porém, na narrativa aqui explorada, o autor descreve o codesign como um processo de design ativo, de saber ouvir e propor entre diferentes disciplinas (transdisciplinar) e partes 
interessadas. Nesse processo, o designer, sendo o profissional dotado de cultura específica de design, figura-se dentro do design especialista, analisando, refletindo, interpretando e criando conhecimento, visões e críticas, que se concretizam em propostas viáveis. Já os demais participantes, dentro do conceito de design difuso, são indivíduos com capacidades humanas naturais de senso crítico, criatividade e senso prático, que, por meio do diálogo, contribuem para criação de propostas.

Este é um modo de pensar e agir do design que tem sido fortemente relacionado, nas organizações contemporâneas, como um caminho promotor de acesso à economia criativa. Todavia, é no design especialista, no qual métodos e ferramentas são cultivados e avaliados quanto ao seu uso eficaz, que uma cultura emergente de design vem surgindo. "O design emergente é uma maneira de interpretar o design e o design que ainda não é popular, mas que está se expandindo e, para todos os efeitos, será o design do século XXI" (MANZINI, 2016, p. 52). O autor afirma ser esse um processo de aprendizagem social, no qual todas as coisas feitas e pensadas pelo modo convencional no século XX terão que ser reinventadas, diante das evidências de limites do planeta e das rápidas mudanças conectivas.

O design emergente é uma abordagem orientada para problemas, cujas características definidoras não são produtos, serviços ou artefatos comunicativos que produz, mas as ferramentas e métodos que usa para lidar com questões de interações complexas, que são, ao mesmo tempo, questões ambientais, sociais, econômicas, políticas etc.: o "foco do design mudou de 'objetos' (significando produtos, serviços e sistemas) e para 'modos de pensar e fazer' (significando métodos, ferramentas, abordagens e, como veremos, projetar culturas)" (MANZINI, 2016, p. 53). É neste tipo de design, emergente, que o sociólogo Arturo Escobar (2018) traz uma contribuição.

$\mathrm{Na}$ obra "Design Autônomo e o Emergente", Escobar (2018, p. 139) diz existir "um reconhecimento esperançoso do caráter multidimensional do design como material, cultural, epistêmico, político e ontológico, tudo de uma vez. Em suma, o design está sendo reconhecido como uma prática decisiva de criação de mundo". Ele pondera que parece existir um número crescente de teóricos de design assumindo um papel mais consciente e construtivo nos processos de concepção de mundos. Um dos fatores que mostra isso, diz Escobar, é que estamos testemunhando uma reorientação da teoria e prática do design, na vontade de boa parte de designers de todo mundo em se envolver mais profundamente em questões emergenciais. Desse modo, o autor considera o design como central para situações de crises, pois é ele que cria coisas novas para um enfrentamento imaginativo e eficaz. Tratase de reinvindicações relacionais mais explícitas entre o design e uma série de questões, incluindo: democracia, imaginação especulativa, ativismo, inclusão de comunidades mais heterogêneas, e definições colaborativas e participativas.

É neste contexto que se pondera a emergência da COVID-19 como uma situação reveladora do interesse do design em atuar como agente de mudança.

\section{Design e a emergência da COVID-19}

Com a situação provocada pela COVID-19, ações de design foram mobilizadas em todo o mundo. No Brasil, o Museu Casa Brasileira (MCB) e o grupo de pesquisa de Design em Ação da Faculdade de Arquitetura e Urbanismo da Universidade de São Paulo (FAU/USP) promoveram juntos o "Desafio Internacional Semeando Ideias", que tinha como objetivo destacar propostas de design capazes de atuar na situação emergencial da COVID-19. Essa ação foi estimulada pela iniciativa "Design for Emergency" do Center for Design da Northeastern University, liderada pelos pesquisadores Sara Colombo e Paolo Ciucarelli, que "busca congregar o levantamento de iniciativas simultâneas, em diversos países, de modo a engajar designers a proporem soluções compartilhadas em plataforma aberta, que podem ser implementadas por empreendedores de qualquer país" (REVISTA PROJETO, 2020, p. 1).

Antes de lançar o Desafio, segundo a fonte, a FAU também realizou uma pesquisa com mais de 2 mil pessoas de todas as regiões, as quais relataram suas experiências durante o período de distanciamento social, sendo que, com isso, foram mapeados seus medos, problemas, esperanças e hábitos, que se transformaram com a situação vivida. Os resultados dessa pesquisa e outras internacionais podem ser acessados no site da Design for Emergency. A Figura 1 exemplifica um conjunto de informações mapeadas e compiladas sobre as necessidades, os desejos e as emoções dos indivíduos pesquisados. 


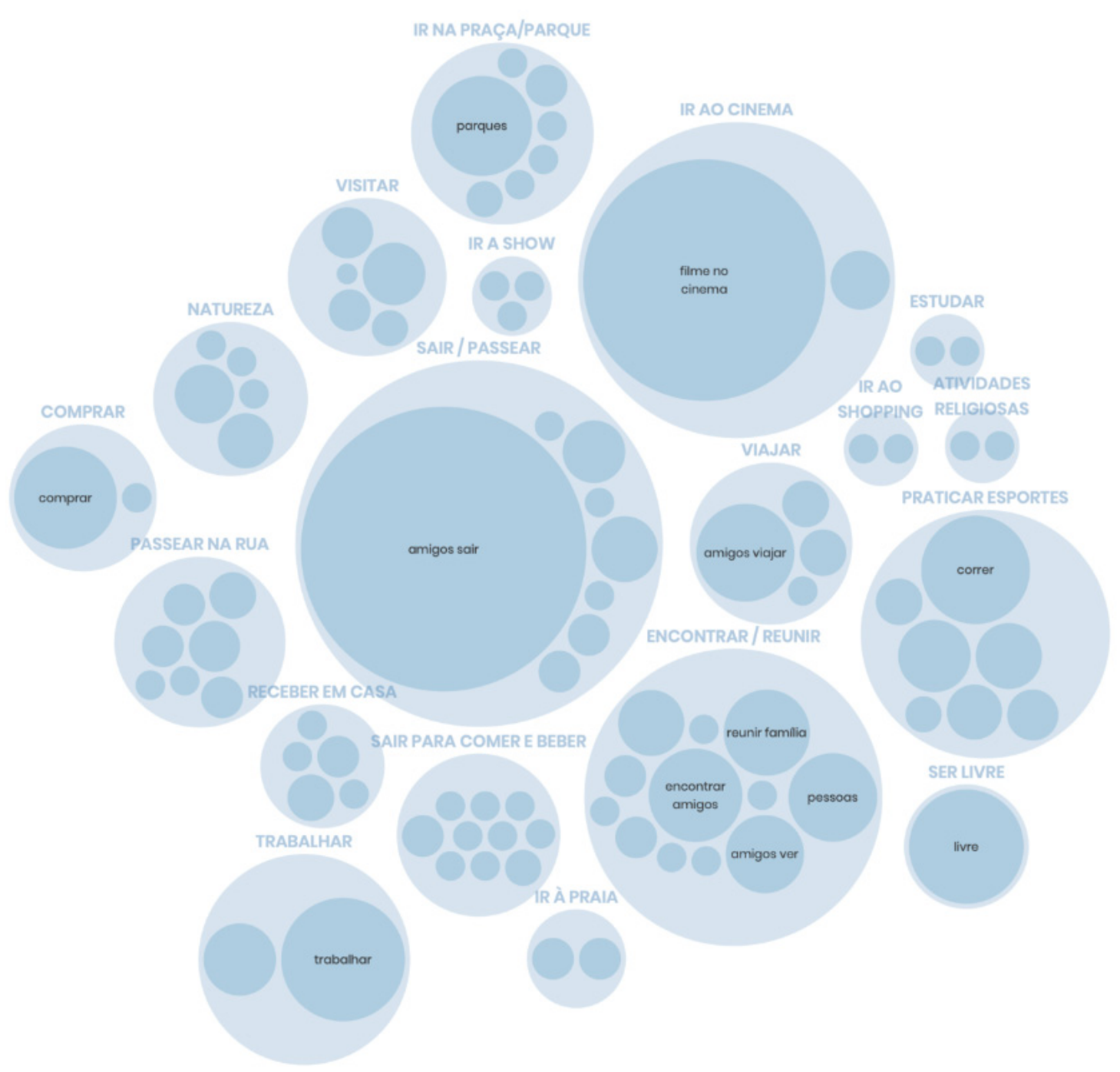

Figura 1 - Necessidades, desejos e emoções de 2 mil indivíduos durante a pandemia da COVID-19. Fonte: Dados da FAU/USP disponíveis em Design for Emergency (2020).

Outra iniciativa lançada foi a COVID-19 Design Challenge (2020a), pela World Design Organization (WDO), IBM Design e Design for America (DFA), que mobilizou mais de 225 designers de 33 países para contribuir com desafios de superação da crise pandêmica instaurada: mais de 180 desafios foram levantados coletivamente e, em seguida, foram agrupados em 7 clusters. Com isso, as equipes de projeto formadas conceberam propostas. Todos os resultados alcançados estão disponíveis em código aberto no site do evento, a fim de conectar potenciais interessados.

A Figura 2 demonstra a proposta de cartões postais para idosos isolados (Postcards for isolated elders) desenvolvida no desafio, que visa promover por meio dos postais "conexões ricas entre idosos isolados e suas comunidades mais amplas, reforçando a importância do distanciamento físico e práticas de higiene seguras (COVID-19 Design Challenge, 2020b). 


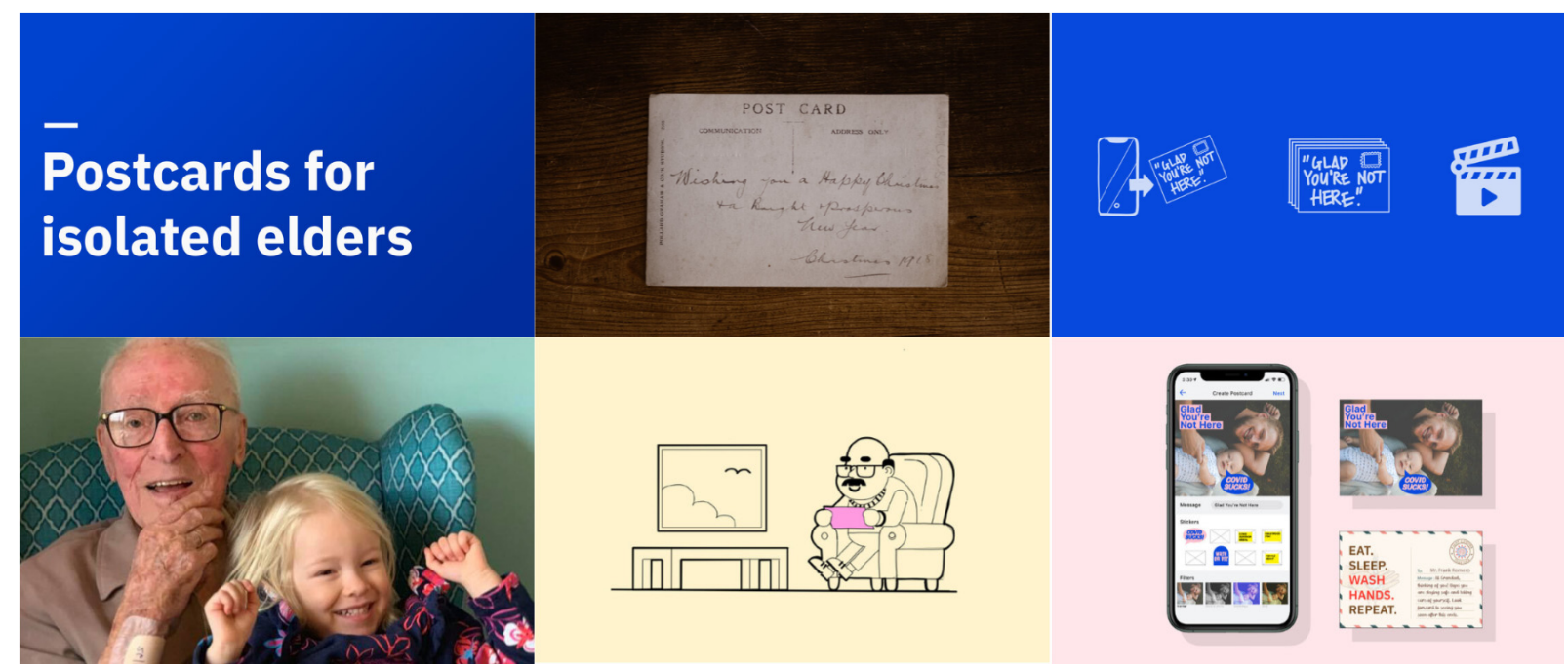

Figura 2 - Design com código aberto de cartões postais para idosos isolados pela COVID-19. Fonte: COVID-19 Design Challenge (2020b).

Essa proposta insere-se na iniciativa de projetos para comunidades vulneráveis diante da situação causada pelo coronavírus. Os idosos são um dos grupos de indivíduos mais suscetíveis aos efeitos mais graves da doença; por outro lado, também sofrem emocionalmente com o isolamento social. Assim, gestos simples de atenção, afeto e cuidado podem levar, além de informação, bem-estar para essa parte da população.

O Desafio Internacional Semeando Ideias e COVID-19 Design Challenge são apenas dois exemplos de ações de mobilização de designers mundialmente para agir sobre a emergência da pandemia instaurada. Desta forma, reconhecendo a existência de tantas outras iniciativas globais, bem como a importância do agir estratégico do design no enfrentamento da COVID-19, o Strategic Design Research Journal (SDRJ), uma publicação da Universidade Vale do Rio dos Sinos (UNISINOS) em parceria com redes internacionais de pesquisa como The Learning Network on Sustainability (LENS); DESIS Network; Cumulus Creative Linking e WDO, lançou um chamada internacional de trabalhos sobre "Design Contributions for the COVID-19 Global Emergency" (Contribuições do Design para a Emergência Global COVID-19). O objetivo da chamada é enriquecer o debate sobre o papel do design no enfrentamento de emergências globais complexas.

A perspectiva dos editores da edição especial do $S D R J$ é que:

Existe uma percepção generalizada de que esta crise mundial mudará todos os aspectos de nosso modo de viver e de nos relacionarmos. Governos, empresas, ONGs, comunidades e indivíduos já estão dedicando seu tempo para refletir os cenários futuros, criando soluções que possam permitir uma transição para o novo mundo que pode vir após a pandemia. Ao contribuir para os desafios contínuos da pandemia, a comunidade de Design também pode contribuir com seu raciocínio abdutivo, com propostas para novos cenários nas consequências pós-pandêmicas. (ROSSI et al., 2020, p. 1)

Assim, os editores consideraram receber da comunidade internacional manuscritos sobre diversos aspectos da situação da COVID-19 instaurada, tais como: estudos de casos; projetos; experiências; investigações fenomenológicas; soluções socialmente inclusivas; relações entre o design e modelos econômicos mais resilientes e sustentáveis durante e pós-pandemia; estudos de abordagens orientadas pela tecnologia e pelo design; estudos de cenários futuros; avanços metodológicos que o design ainda poderá considerar nas próximas décadas e estratégias de ensino superior adotadas com o impacto da COVID-19 na educação. O debate sobre esse volume gerado pelo SDRJ poderá ser objeto de uma narrativa futura, uma vez que a temporalidade de publicação deste artigo e da edição especial da revista são distintas. Muito embora já se saiba a totalidade de trabalhos submetidos, sendo essa de mais de 100 artigos recebidos, considerando envios de mais de 20 países. 
Contudo, sinais de um importante caminho para o design, diante dos ensinamentos da COVID19, podem ser encontrados na carta escrita por Manzini (2020) para a Rede DESIS. Segundo o designer, a inovação social que se tornou conhecida nas últimas décadas terá que evoluir para algo novo, seguindo as mudanças sociais e culturais de uma sociedade on-line. Será preciso surgir propostas de design para habitar um novo espaço híbrido, entre mundos físicos e digitais; propostas que consideram a rede para fazer algo juntos, como um novo modo de interagir e agir sobre o mundo real. Trata-se de uma nova "sociabilidade" capaz de cultivar uma rede de relacionamentos entre "vizinhos", um grupo localizado e bem definido, em um espaço físico-digital.

Durante a pandemia, organizações que já se caracterizavam como híbridas foram aquelas que, na visão do autor, se mostraram mais coesas e resilientes aos efeitos da crise gerada. Dentre os exemplos dessas organizações está o grupo Renner, que vem investindo em tecnologia para se relacionar com seu público e trabalhar em um formato híbrido de contato via internet, aliado com a entrega ou a retirada em loja. Além disso, a empresa promoveu diversas iniciativas em prol de todo ecossistema da marca, como a suspensão das demissões, a produção e doação de equipamentos de segurança, e potencializou suas inciativas relacionadas à sustentabilidade.

Outro exemplo de destaque no mercado brasileiro é a varejista Magazine Luiza, que durante a pandemia desenvolveu e promoveu o sistema de marketplace, modalidade digital onde empresas são habilitadas para vender seus produtos através do site e da infraestrutura da varejista. Vale ressaltar também a grande quantidade de pequenos comércios e restaurantes que trabalharam para manter o relacionamento e criar meios de se comunicar com seus clientes, utilizando-se do mundo digital como um elemento crucial para a sobrevivência dos seus negócios físicos.

Todavia, a carta do designer para a Rede DESIS explicita que:

A construção dessas novas comunidades requer uma visão e algumas habilidades específicas para decidir como agir, ouvir os feedbacks (formar os outros e o ambiente) e reorientar as ações. Requer também imaginar e desenvolver experimentos sociais e institucionais. E, não menos importante, requer uma reflexão mais profunda sobre a relação entre nós, seres humanos, e o que até agora chamamos de "natureza" (MANZINI, 2020, p. 3).

Uma reflexão já nesse sentido é a do escritor, ambientalista e líder indígena Ailton Krenak:

Esse vírus está discriminando a humanidade. Basta olhar em volta. O melão-de-sãocaetano continua a crescer aqui do lado de casa. A natureza segue. O vírus não mata pássaros, ursos, nenhum outro ser, apenas humanos. Quem está em pânico são os povos humanos e seu mundo artificial, seu modo de funcionamento que entrou em crise (KRENAK, 2020, p. 6).

Considerando a crítica trazida na narrativa de Krenak ao contexto recente da humanidade, abre-se o seguinte debate: ao sugerir o abandono do antropocentrismo, é feita uma reflexão sobre a responsabilidade do mundo artificial que os humanos construíram. Torna-se importante refletir que essa linha de pensamento, voltada ao ecossistema, pode ser um relevante caminho para uma ressignificação da vida em comunidade e da forma de viver e interagir, considerando, para isso, os efeitos do individualismo gerados sobre o mundo natural.

Nesse sentido, no design, "hoje, muitas narrativas de transição reconhecem os efeitos deletérios do individualismo liberal intensificado, [...] abrigando, na medida do possível, visões de transição que enfatizam a necessidade de recomunalizar a vida social" (ESCOBAR, 2018, p. 142). Como a visão de Manzini (2017), que afirma sobre a necessidade de emergir uma nova civilização, não apenas para resolver problemas, mas também para estar relacionada a uma ideia de bem-estar. Essa ideia, por sua vez, baseada em uma nova ecologia de relações entre as pessoas e o meio ambiente, sustentada pela inovação social, que deve dar passos concretos em direção à sustentabilidade.

Por outro lado, o mundo artificial, citando Moreira e Schlemmer (2019), tem promovido transformações sociais importantes: são novos modos de viver, conviver e aprender, tanto de natureza analógico-geográfica como digital. Sendo que: 
Todas essas transformações vêm contribuindo para nos aproximar e nos unir numa grande comunidade global ciber-física, potencializando a comunicação, a colaboração e a cooperação entre organizações de diferentes naturezas. Essa potencialidade torna possível reunir nações e pessoas para pensar na complexidade ecossistêmica do mundo atual e compreender como a relação entre atores humanos $(\mathrm{AH})$ e não humanos (ANH), com o meio ambiente orgânico e/ou inorgânico que habitam, e pelo qual também são habitados, se transforma (MOREIRA e SCHLEMMER, 2019, p. 6).

Dentro desse contexto, destaca-se a visão do sociólogo Massimo Di Felice, que explica a invenção da externalidade pela tradição ocidental:

[...] baseada no mito bíblico da superioridade da espécie humana sobre as demais ou, no caso da filosofia, na redução dos elementos não humanos a objeto, "a coisa" [...]. A supremacia do humano sobre a natureza e o território foi, por séculos, o pressuposto da condição habitativa (DI FELICE, 2011, p. 10).

Contudo, o autor já indicava que uma nova interação se instaurava com o meio ambiente, e que essa exigia uma nova teoria da ação, determinada pelo autor como Atópica. "O habitar atópico se configura, assim, como a hibridação, transitória e fluida, de corpos, tecnologia e paisagem, e como o advento de uma nova tipologia de ecossistema, nem orgânica, nem inorgânica, nem estática, nem delimitável, mas informativa e imaterial" (DI FELICE, 2009, p. 291). Com isso, emerge uma nova relação, "que se afasta tanto do paradigma tecnocêntrico, quanto antropocêntrico, contribuindo para o surgimento de cultura planetária e ecossistêmica" (SCHLEMMER e MOREIRA, 2020, p. 702).

Voltando ao design de Manzini (2020) e a crise do Covid-19, de fato o que emerge, além de um habitar híbrido (físico-digital), é a compressão que não há fora ou dentro e que todos somos natureza, porém até se dar uma superação dessa visão antropocêntrica, muito dever ser experimentado e tangibilidade na visão do autor.

Então, se espera que as ações das entidades destacadas aqui (Design Contributions for the COVID-19 Global Emergency - SDJR Unisinos, LENS, DESIS, Cumulus; Desafio internacional semeando ideias - Design for Emergency e FAU/USP; COVID-19 Design Challenge de WDO, IBM Design e $D F$ ) contribuam de maneira a tornar a prática do design estratégico uma cultura cada vez mais emergente e capaz de lidar com situações complexas, como se revelou a crise pandêmica COVID-19.

\section{Considerações finais}

A intenção deste artigo foi trazer à tona conceitos que embasaram o surgimento do design estratégico, na visão de Mazini e como essa abordagem teórica-metodológica evoluiu num recorte (1992-2020) desde o Prometeu do Cotidiano (Prometheus of the Everyday) de Manzini e Cullars (1992) até novas contribuições que surgiram com a emergência de um agir estratégico diante da pandemia da COVID19. A demanda de um enfrentamento crítico-criativo sobre os impactos gerados e deixados pelo coronavírus reforçou a existência de uma cultura emergente de design, interessada em agir em situações de interações complexas.

Assim, após apresentar alguns dos principais conceitos norteadores dessa cultura de design, o artigo demostrou que, com a emergência da Covid-19, uma série de iniciativas globais aconteceram, mobilizadas por entidades organizacionais de design, a fim de contribuírem com o cenário alarmante gerado. Foram estudos que surgiram desde pesquisas de como as pessoas estavam se sentido até propostas de sistema-produtos-serviços para agir no bem-estar de populações mais afetadas, como idosos isolados socialmente. Também a edição especial da SDRJ - Strategic Design Research Journal evidenciou que mais de uma centena de estudos foram concebidos para colaborar com o enfrentamento das situações adversas provocadas pelo coronavírus. Futuramente, esses estudos, quando publicados, possibilitarão identificar as diferentes dimensões da humanidade, que algumas comunidades de design no mundo, atuaram para contribuir com o cenário de crise deixado, 
permitindo, também, com isso, expor, ainda mais uma cultura de design que se forma para agir na emergência.

Por fim, é feito um convite à reflexão do papel do designer na construção de um mundo, no qual a visão do ecossistema torna-se protagonista das ações, unindo agentes humanos e não humanos. Manzini (2020), por exemplo, neste caminho, aborda um fortalecimento dos conceitos de design para a inovação social e para a sustentabilidade, em um agir dialógico, com foco no surgimento de novas relações sociais híbridas, que permeiam o mundo físico e o digital, em respostas sociotécnicas. Com isso, o principal achado deste artigo é compreender, justamente, a necessidade de repensar o papel do ser humano não mais distante ou separado da natureza, mas, sim, como parte dela, partindo de uma visão ecossistêmica, capaz de tornar as ações mais estratégicas e resilientes em situações de crise, tal como se mostrou os lastros deixados pela crise pandêmica da SARS-CoV-2. Como limitação deste estudo é importante salientar que foram debatidos elementos de uma das possíveis culturas relacionadas ao design estratégico e que outras abordagens e visões também podem ser exploradas em estudos futuros.

Strategic design and the emergence of COVID-19

Abstract: The COVID-19 pandemic crisis ended up revealing the complexity of adverse situations and their impact on different layers of human existence. In this article, the importance of strategic design action is questioned. Therefore, aiming to talk about the emergence and evolution of the concept of strategic design as an emerging culture that is formed to face complex situations. The study takes place through a narrative and chronological review of works by Ezio Manzini, with specific collaborations by Ana Meroni and Arturo Escobar, until arriving at a group of international design initiatives, interested in contributing strategically to the pandemic scenario experienced. In general, the rhetorical conceptual views pointed out by Manzini show the relevance of a design culture capable of operating in the emergency, resignifying and hybridizing ecosystem relations between physical and digital worlds and proposing socio-technical solutions.

Keywords: Strategic Design; COVID-19; Complex Situations; Design Culture; Hybridity

\section{Referências}

COVID-19 Design Challenge. Home. Disponível em: https://covid19designchallenge.org/. Acesso em: 25 jul. 2020a.

COVID-19 Design Challenge. Vulnerable Communities: Postcards for isolated elders. Disponível em: https://covid19designchallenge.org/vulnerable-communities/. Acesso em: 25 jul. 2020b.

DESIGN FOR EMERGENCY. Analysis: Brasil. Disponível em: https://www.designforemergency.com/analysis/br. Acesso em: 25 jul. 2020.

DI FELICE, Massimo. Pós-complexidade: as redes digitais vistas a partir de uma perspectiva reticular. Entrevista ao Instituto Humanitas: Unisinos, nov. 2011.

DI FELICE, M. Paisagens pós-urbanas: o fim da experiência urbana e as formas comunicativas do habitar. São Paulo: Annablume, 2009.

ESCOBAR, A. Autonomous design and the emergent transnational critical design studies field, in:

Strategic Design Research Journal, 11 (2), 2018.

KRENAK, A. O amanhã não está à venda, Companhia das Letras. São Paulo: 2020. 
MADEIRA, M. G. Economia criativa. Implicações e desafios para a política externa brasileira. Brasília: FUNAG, 2014.

MANZINI, E. Design para a inovação social e sustentabilidade: Comunidades criativas, organizações colaborativas e novas redes projetuais. Cadernos do Grupo de Altos Estudos, Rio de Janeiro: Epapers, v. 1, 2008.

MANZINI, E. Design: quando todos fazem design - uma introdução ao design para a inovação social, Editora Unisinos. São Leopoldo: 2017.

MANZINI, E.; CULLARS, J. Prometheus of the everyday: the ecology of the artificial and the designer's responsibility, in: Design Issues, Cambridge, v. 9, n. 1, p. 5-20, 1992.

MANZINI, E. Design cultures and dialogic design, in: Design Issues, Cambridge, v. 32, n. 1. p. 5259, 2016.

MANZINI, E. Introduction, in: MERONI, A.; SANGIORGI, D. Design for Services, [S.I.]: Gower Publishing, 2011.

MANZINI, E. COVID-19 and Social Innovation: Contactless sociability and hybrid communities of place, in: DESIS NETWORK - Design for Social Innovation and Sustainability. Disponível em: https://www.desisnetwork.org/2020/04/07/social-innovation-contactless-sociability-and-hybridcommunities-of-place/. Acesso em: 7 jul. 2020.

MANZINI, E. Strategic design for sustainability: towards a new mix of products and services, in: Proceedings First International Symposium on Environmentally Conscious Design and Inverse Manufacturing. IEEE, p. 434-437, february, 1999.

MANZINI, E. Strategic design for sustainability: instruments for radically oriented innovation, in: JÉGOU, F.; MANZINI, E. Sustainably everyday: scenarios of urban life, Edizioni Ambiente. Milano, p. 231-234, 2003.

MANZINI, E.; PENIN L.; GONG, M.; CIPOLL, C.; M'RITHAA, M.; MENDOZA, A. The DESIS Network: Design and Social Innovation for Sustainability, in: The Journal of Design Strategies: Change Design. v. 4, n. 1. p. 14-21, Spring, 2010.

MERONI, A. Strategic design: where are we now? Reflection around the foundations of a recent discipline. Strategic Design Research Journal, v. 1, n. 1, p. 31-38, 2008.

MERONI, A.; SANGIORGI, D. Design for Services, [S.I.]: Gower Publishing, 2011.

MOREIRA, J. A.; SCHLEMMER, E. Por um novo conceito e paradigma de educação digital online.

Revista UFG, v. 20, 2020.

NEWBIGIN, J. What is the creative economy? From 'creative industries' to 'creative economy' - how the idea of creative industries and the creative economy has changed in the last 20 years. Creative Economy, British Council, UK, 2016. Disponível em: http://creativeconomy.britishcouncil. org/guide/what-creative-economy/. Acesso em: dez. 2016.

NEWBIGIN, J.; ROSSELLÓ, P.; WRIGHT, S. The creative economy: an introductory guide. British Council, UK, 2010

REVISTA PROJETO. MCB e FAUUSP promovem o Desafio Internacional Design for

Emergency - Semeando Ideias. Disponível em: https://revistaprojeto.com.br/noticias/mcb-e-fauusppromovem-o-desafio-internacional-design-for-emergency-semeando-ideias/. Acesso em: 25 jul. 2020.

ROSSI, E.; DI NICOLANTONIO, M.; CESCHIN, F.; MINCOLELLI, G.; SANTOS, A.; KOHTALA, C.; JACQUES, E.; CIPOLLA, C.; MANZINI, E. Design contributions for the COVID-19 global emergency. Disponível em: http://revistas.unisinos.br/index.php/sdrj/pages/view/call. Acesso em: 30 jul. 2020.

SCHLEMMER, E.; MOREIRA, J. A Modalidade da Pós-Graduação Stricto Sensu em discussão: dos modelos de EaD aos ecossistemas de inovação num contexto híbrido e multimodal. Educação

Unisinos, v. 23, n. 4, p. 689-708, 2019. 